\title{
Ueber die Zusammensetzung des menschlichen Fettes. Ein Beitrag zur Analyse der Fette. \\ Von
}

Dr. phil. Hermann Jaeckle.

Leiter der chemischen Station des hygienischen Institutes zu Posen.

(Aus dem königlichen hygienischen Institut zu Posen.)

(Der Redaction zugegangen am 13. Juli 1902.)

Das menschliche Fett ist schon des Oefteren zum Gegenstand ausführlicher Untersuchungen gemacht worden. Beim Studium der einschlägigen Litteratur macht sich jedoch insofern ein Mangel bemerkbar, als einerseits häufig nur ein einzelnes Fett bezw. das Fett eines einzelnen Individuums untersucht wurde und die erhaltenen analytischen Daten als grundlegend für die Zusammensetzung des Menschenfettes in die weitere Litteratur übergegangen sind, andererseits, wenn eine grössere Anzahl von Fetten zur Untersuchung gelangte, deren Analyse sich nur auf die Ermittelung eines einzelnen Bestandtheiles erstreckte. Es kann nun von vornherein vorausgesetzt werden, dass das menschliche Fett in seiner Zusammensetzung und mithin in seinen Eigenschaften ähnlichen individuellen Schwankungen unterworfen ist, wie sie für alle übrigen Säugethierfette constatirt sind. Das Ergebniss der, vorliegenden Untersuchungen bestätigt diese Annahme auch vollkommen. Ein weiterer Umstand, der es angezeigt erscheinen liess, der vorliegenden Frage nochmals eingehend näher zu treten, ist der Umstand, dass die Methodik der Fettanalyse während des in Betracht kommenden Zeitraums höchst werthvolle Bereicherungen erfahren hat, dass diese auf der andern Seite aber erfahrungsgemäss in der analytischen Praxis nicht immer genügend berücksichtigt werden. So kommen immer noch Zahlen über den Gehalt der Fette an ungesättigten bezw. an festen Fettsäuren in die Litteratur, welche nach der Methode von Varrentrapp, also auf Grund der Aether- 
löslichkeit des Bleioleats gewonnen sind, obgleich kaum mehr ein Zweifel darüber bestehen kann, dass die Ergebnisse dieser Methode sich nur zufällig mit den thatsächlichen Verhältnissen decken können.

Auch hierfür werden in dieser Arbeit Belege gebracht werden. Schliesslich sind einige wichtigere Factoren in der Analyse des menschlichen Fettes überhaupt noch nicht berücksichtigt worden, so vor Allem der Gehalt an Gholesterin und Lecithin.

F. Hofmann ${ }^{1}$ ) bestimmte den Gehalt des Menschenfettes an freien Säuren. Er schmolz das Fett bei $60-70^{\circ}$ aus und fand in einem Falle nur $0,003 \%$ freie Säure (als $\mathrm{H}_{2} \mathrm{SO}_{4}$ ausgedrückt), in einem zweiten Fall 0,062\%. Der Gehalt des Leberfettes an freier Säure dagegen betrug. im Maximum 1,4482 (als $\mathrm{H}_{2} \mathrm{SO}_{4}$ berechnet).

L. Langer ${ }^{2}$ ) verfolgte die Thatsache, dass das Fett der Neugeborenen sich durch grössere Consistenz von dem Fett der Erwachsenen unterscheidet. Er erhielt das erstere durch Ausschmelzen aus dem panniculus adiposus als eine weisse, ziemlich feste, bei $45^{\circ}$ schmelzende Masse, während das letztere von gelber Farbe war und bei Zimmertemperatur zum grösseren Theil flüssig blieb. Langer verseifte zur näheren Untersuchung von beiden Fetten je $1 \mathrm{~kg}$ (er hat demnach mindestens bei dem Fett von Neugeborenen ein Mischfett von mehreren Individuen zur Untersuchung verwendet) und zerlegte die Seife mit Salzsäure. Die Fettsäuren aus dem Kinderfett schmolzen bei $51^{\circ}$, die aus dem Fett von Erwachsenen bei $38^{\circ}$. Die Trennung der Oelsäure von den festen Säuren führte Langer vermittelst der Bleisalze durch. Die festen Säuren enthielten nur Palmitinsäure und Stearinsäure, die Trennung dieser beiden erfolgte durch fractionirte Fällung der Magnesiumsalze.

1) Sonderabdruck aus der Festschrift zum Ludwigs-Jubiläum nach Hirsch's Jahresbericht X (1875) 1, S. 182.

2) Ueber die Zusammensetzung des menschlichen Fettes in verschiedenen Lebensaltern. Sitzungsbericht der Wiener Akad. d. Wissensch. III. Abth., Juniheft. Nach Hirsch's Jahresbericht XVI (1881) 1, S. 131. 
Langer fand folgende Zusammensetzung der Fette:

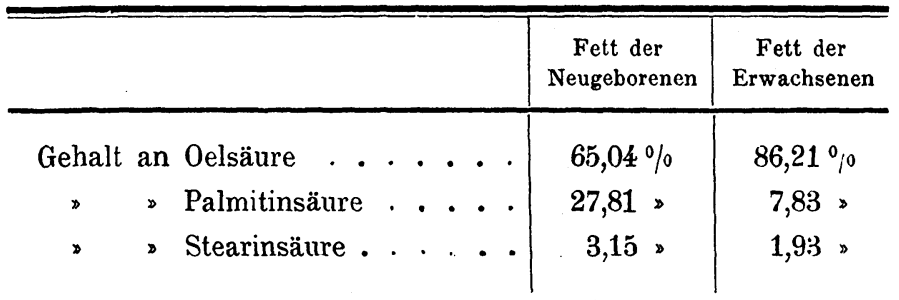

Der Gehalt des Fettes an festen Säuren ist demnach beim Kind ungefähr 3 mal grösser als beim Erwachsenen. Bei den festen Fettsäuren überwiegt in beiden Fällen weitaus die Palmitinsäure; das Verhältniss der Palmitinsäure zur Stearinsäure ist beim Kind gleich 9:1, beim Erwachsenen 4:1. An flüchtigen Fettsäuren konnte Langer im Kindesfett Capronsäure und Buttersäure nachweisen; das Fett der Erwachsenen enthielt keine zur Untersuchung hinreichende Menge flüchtiger Säuren.

A. Lebedeff ${ }^{1}$ ) verseifte Fette im Kohlensäurestrom, fällte die Seifen mit Bleiacetat und behandelte die getrockneten Niederschläge mit Aether. Aus den derart getrennten Bleisalzen machte er dann die Säuren mit Schwefelwasserstoff frei. Er fand so für Menschenfett aus verschiedenen Geweben bezw. Organen folgende Werthe:

\begin{tabular}{|c|c|c|}
\hline & Oelsäure & $\begin{array}{l}\text { Palmitinsäure } \\
\text { u. Stearinsäure }\end{array}$ \\
\hline Fett aus dem Unterhautzellgewebe . & $80,0 \%$ & $16,7 \%$ \\
\hline Fett aus Fettembolie der Lunge. . & 66,7 . & 28,7 . \\
\hline Darmfett . . . . . . . . . & 74,4 , & 22,0 \\
\hline Lipomfett . . . . . . . . & 76,1 & 13,7 \\
\hline Fett aus Fettleber ...... & $\begin{array}{l}68,7 \gg \\
60,4 \gg\end{array}$ & $\begin{array}{l}26,6 \\
32,8\end{array}$ \\
\hline
\end{tabular}

Von flüchtigen Fettsäuren fand Lebedeff im Menschenfett Capronsäure; er überzeugte sich ferner, dass kleine Mengen flüchtiger Fettsäuren (zwischen 0,02-0,2\%) in jedem Fett vorkommen.

1) Diese Zeitschrift, Bd. VI, S. 142. 
O. Schulz und G. Schwalbach ${ }^{1}$ ) untersuchten das Fett eines ungewöhnlich grossen Lipoms $(28 \mathrm{~kg})$, nachdem dieses 14 Tage in etwa $40 \%$ igem Spiritus gelegen hatte. Das Fett war geruchlos und bei $35^{\circ}$ vollständig flüssig; bei Zimmertemperatur wurde es zum kleinen Theil fest. Es enthielt Cholesterin und $7,312 \%$ freie Fettsäuren. Aus $100 \mathrm{~g}$ Fett erhielten die Verfasser $94 \mathrm{~g}$ Fettsäuren und 9,9 g Glycerin. Das Gemisch der aus dem Fett isolirten Fettsäuren hatte folgende Zusammensetzung:

$$
\begin{array}{llc}
\text { Oelsäure . . . . . . . . } & 65,57 \% \\
\text { Stearinsäure . . . . . } & 29,84 \% \\
\text { Palmitinsäure } & \text {. . . } & 4,59
\end{array}
$$

W. G. Ruppel ${ }^{2}$ ) untersuchte ein Lipom, das $579 \mathrm{~g}$ wog. Das Fett desselben bildete eine gelbliche, dickflüssige Masse, die bei $28^{\circ}$ mit goldgelber Farbe flüssig war. Es hatte nachstehende Zusammensetzung:

$$
\begin{aligned}
& \text { Freie Fettsäuren . . . . } 1,0 \% \\
& \text { Oelsäure . . . . } 65,0 \% \\
& \text { Feste Fettsäuren . . . . 23,5 }
\end{aligned}
$$

Flüchtige Fettsäuren, Glycerin und Unverseifbares 10,5\%. Die festen Fettsäuren bestanden grösstentheils aus Stearinsäure, die flüchtigen enthielten Caprinsäure und vermuthlich Buttersäure.

C. A. Mitchell ${ }^{3}$ ) erhielt das Menschenfett durch Ausschmelzen bei möglichst niedriger Temperatur als fahlgelbes Oel von geringerer Consistenz als Butter. Die Untersuchung des Fettes ergab folgende Werthe:

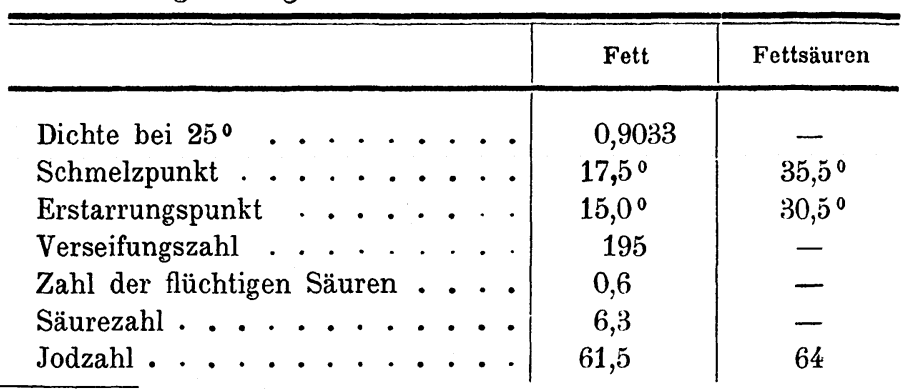

1) Pflüger's Archiv, Bd. 55, S. 231.

2) Zeitschrift f. Biologie, Bd. 31, S. 101.

3) The Analyst 21, 171. Ref. Chem. Centralblatt, 1896. II. 498. 
Das Fett enthielt 50,2\% feste Fettsäuren und $49,8 \%$ flüssige Fettsäuren, die Jodzahl der ersteren betrug 37 , die der letzteren 92,1. Die flüssigen Säuren scheinen demnach neben der vorwiegenden Oelsäure noch eine geringe Menge einer höher ungesättigten Säure, vielleicht Linolsäure, $\mathrm{zu}$ enthalten. Da Mitchell durch Krystallisation der festen Säuren aus verdünntem 70\% igen Alkohol eine Fraction vom Schmelzpunkt 50,50 erhielt, folgerte er daraus, dass vermuthlich neben der Palmitinsäure und geringen Mengen von Stearinsäure noch Myristinsäure vorliegt.

W. Lindemann ${ }^{1}$ ) untersuchte das Verhältniss zwischen der Zusammensetzung des Fettes aus normalen und aus fettig entarteten Organer.

W. Knöpfelmacher ${ }^{2}$ ) und M. Thiemich ${ }^{3}$ ) bestimmten zur Aufklärung der Sklerembildung den Oelsäuregehalt der Fette von Kindern vermittelst der Jodadditionsmethode nach v. Hübl.

Knöpfelmacher fand u. A. im Fett des Neugeborenen $43,3 \%$ Oelsäure, gegen 65\% im Fett eines älteren Kindes. Thiemich constatirte beträchtliche Schwankungen in der Jodzahl der Fettsäuren aus einer grösseren Anzahl von Neugeborenenfetten; als Maximalwerth erhielt er die Jodzahl 49,4.

Diese Studien über den Oelsäuregehalt der Fette von Kindern setzte F. Siegert ${ }^{4}$ ) fort. Im Interesse einer weitergehenden Verwendbarkeit der Ergebnisse dieser umfangreichen Arbeit ist es zu bedauern, dass Siegert nicht eben glücklich war in der Wahl der Darstellungsmethode seines Untersuchungsmaterials. Er extrahirte zunächst das fein zerhackte Unterhautfettgewebe mit Alkohol von steigendem Gehalt bei etwa $40^{\circ}$, schliesslich mit siedendem Alkohol und dann mit Aether. Das so erhaltene Extract verseifte er, zerlegte die Seifen, wusch die Säuren bis zur neutralen Reaction und trocknete sie dann "gründlich». In den derart vorbehandelten

1) Zeitschrift f. Biologie, Bd. 38, S. 405.

2) Nach Hirsch's Jahresbericht XXXII (1897) 1, S. 142.

3) Diese Zeitschrift, Bd. XXVI, S. 189.

4) Beiträge zur chem. Pathologie und Physiologie, Bd. I, S. 183. 
Fettsäuren bestimmte Siegert die Jodzahl nach Ephraim, also mit einer Lösung von Jodmonochlorid, wobei er es für zweckmässig fand, die übliche Concentration der Thiosulfatlösung $\mathrm{zu}$ verdoppeln. Diese Abänderung dürfte kaum einen Anklang finden, da ohnedies bereits die. Ablesungsfehler sich bei der Berechnung der Jodzahl in unliebsamer Weise geltend machen. ${ }^{1}$ ) Durch die vorgeschlagene Abänderung wird dieser Fehler von vornherein verdoppelt, ein Umstand, der sich darin zu erkennen gibt, dass die Kontrollanalysen Siegert's nach seiner Angabe "meist um höchstens 1,5» in der Jodzahl differirten. Da ferner Siegert weniger den absoluten Gehalt der Fette an Oelsäure, als vielmehr die Veränderung des Oelsäuregehaltes mit steigendem Lebensalter klarlegen wollte, so wäre es ungleich sicherer und bequemer gewesen, im Interesse der möglichsten Erhaltung der Oelsäure auf die Extraction der letzten Fettmengen aus dem Zellgewebe zu verzichten und ausserdem unmittelbar die Jodzahl der Fette selbst zu bestimmen anstatt derjenigen der Fettsäuren. Denn dass an der Jodabsorption die Alkohole der Fette gar nicht betheiligt sind, ist zur Genüge bewiesen. Dass ferner durch diese Vorbehandlung der Fette und Fettsäuren die Oelsäure, deren doppelte Bindung als die weitaus empfindlichste Angriffstelle der Fette erkannt ist, stark in Mitleidenschaft gezogen werden musste, dürfte kaum zu bestreiten sein. Boemer ${ }^{2}$ ) hat u. A. nachgewiesen, dass der Einfluss des Luftzutritts beim Trocknen der Oelsäure ein ausserordentlich grosser ist. Er trocknete Oelsäure im Kohlensäurestrom und einen andern Theil derselben Säure nur eine Viertelstunde im Dampftrockenschrank. Im letzten Fall erhielt er bereits eine um mehr als zwei Einheiten niedrigere Jodzahl. Siegert's Zahlen, die zwar unter sich einigermaassen vergleichbar sind, müssen also mit Sicherheit durchweg viel zu niedrig sein. Siegert erhielt folgende Werthe:

1) Vergl. Forschungsberichte über Lebensmittel etc., Bd. I, S. 318.

2) Zeitschr. f. Untersuchung der Nahrungsmittel etc. 1898. 541. 


\begin{tabular}{|c|c|c|c|c|c|}
\hline \multicolumn{2}{|c|}{ Alter } & $\begin{array}{c}\text { Zahl der } \\
\text { Fette }\end{array}$ & \multicolumn{2}{|c|}{ Jodzahl } & Mittel \\
\hline Neug & rene & 12 & 38,8 & 49,2 & 43,36 \\
\hline & nat & 7 & 38,1 & 48,7 & 42,5 \\
\hline & nate & 6 & 38,45 & 51,4 & $.46,9$ \\
\hline 3 & $\triangleright$ & 2 & 41,5 & 53,5 & $47, \check{5}$ \\
\hline 4 & $\triangleright$ & 8 & 41,5 & 58,9 & 53,2 \\
\hline ว & $D$ & 3 & 42,3 & 47,8 & $45, \check{0}$ \\
\hline 6 & 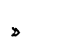 & 4 & 47,0 & $\tilde{0} 1,47$ & $4 \dot{9}, 9$ \\
\hline $7-8$ & $»$ & 4 & 46,1 & $\check{5} 2,9$ & 48,9 \\
\hline 9 & 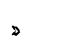 & 2 & ๖̊1,7 & 57,8 & 54,75 \\
\hline $10-11$ & $\gg$ & 2 & $\check{5} 5,5$ & 61,6 & 58,55 \\
\hline 12 & $\gg$ & 2 & 61,0 & 63,7 & 62,35 \\
\hline \multicolumn{2}{|c|}{ Erwachsene } & - & \multicolumn{2}{|c|}{65} & - \\
\hline
\end{tabular}

In die vorliegende Arbeit, deren analytischer Theil bereits im Herbst 1901 abgeschlossen war, wurden nur zwei Kinderfette hineingezogen. Für das Fett eines 3 Tage alten Kindes wurde die Jodzahl 47,3 erhalten, für dasjenige eines 2 bis 3 wöchentlichen Kindes die Jodzahl 58,1. Daraus würden sich unter Zuhülfenahme der Verseifungs- und der Säurezahl die Jodzahlen für die freien Fettsäuren berechnen mit 53,2 bezw. 65,4. In diesen beiden Fällen wurden mithin viel höhere Werthe erhalten, als sie Siegert beobachtet hat. Ja in dem zweiten Falle wäre bereits Siegert's Oelsäuregehalt der Fette von Erwachsenen nach 2-3 Wochen erreicht. Ueberdies war bei den Fetten von Erwachsenen kein einziges Mal eine so niedrige Jodzahl gefunden worden, wie sie Siegert für die Fettsäuren als Norm annimmt. Alles dies erklärt sich leicht aus der Art und Weise, wie Siegert die Fette extrahirt und die freien Fettsäuren dargestellt hat. Trotzdem soll gewiss nicht bestritten werden, dass die Zahlen der Siegert'schen Arbeit unter sich vergleichbar sind, unter der Voraussetzung, dass er alle Fette bezw. Fettsäuren in Bezug auf angewandte Zeit und Temperatur völlig gleich behanđelt hat. Sein Schluss- 
ergebniss, dass der niedrige Oelsäuregehalt der Kinderfette in den ersten Monaten nur wenig zunimmt, dass er gegen Ende des 1. Lebensjahrs sehr rasch ansteigt, und dass schliesslich mit dem Beginn des 2. Lebensjahrs das Fett seine definitive Zusammensetzung erreicht, dürfte trotz des erwähnten Umstandes aufrecht erhalten bleiben können.

Als Aufgabe dieser vorliegenden Studien war in erster Linie die möglichst eingehende Analyse des normalen menschlichen Fettes angenommen worden. Es wurde hierzu das Fett aus dem Unterhautzellgewebe möglichst von Personen verwendet, die an acuten Krankheiten gestorben waren. Daran angeschlossen wurde noch die Untersuchung einer Anzahl von Lipomfetten. Für die überaus liebenswürdige Beschaffung des hierzu nöthigen Materials sei dem Leiter der pathologischanatomischen Abtheilung des hygienischen Instituts, Herrn Professor Dr. Lubarsch, auch an dieser Stelle bestens gedankt.

Zur Gewinnung des Fettes in möglichst unveränderter Beschaffenheit wurde das Fettgewebe zerkleinert, das Fett bei möglichst niedriger Temperatur ausgeschmolzen und die Geweberückstände ausgepresst. Das Rohfett wurde von dem Bodensatz abgegossen, zur Beseitigung des Wassers mit scharf getrockneten Filtrirpapierschnitzeln einige Minuten geschüttelt, alsdann durch getrocknete Papierfilter filtrirt. Alle diese vorbereitenden Operationen wurden bei möglichst niederen Temperaturen und thunlichst unter Luftabschluss durchgeführt.

Es möge zunächst die Aufzählung der Fette und die Angabe ihrer äusseren Eigenschaften folgen:

\section{Fette aus dem Unterhautzellgewebe.}

Fett I: Sehr fettreicher Mann, Alter unbekannt, Todesursache: Unglücksfall. Das Fett ist von kräftig gelber Farbe, es ist bei $15^{0}$ nur zum kleineren Theil fest, bei $32-33^{0}$ vollständig geschmolzen. Der Erstarrungspunkt liegt zwischen $13,2-13,6^{0}$.

Fett II: 60. Jahre alter Mann, Unterhautzellgewebe fett- 
arm. Krankheit: Schwere Darmentzündung. Das Fett ist bei $15^{0}$ völlig erstarrt und von gelblichweisser Farbe.

Fett III: 47jähriger Mann. Unterhautzellgewebe sehr fettreich. Krankheit: Magenkrebs. Das Fett ist bei $15^{0}$ dickflüssig, ungefähr zur Hälfte fest, von dunkelgelber Farbe.

Fett IV: 40jähriger Mann, Unterhautzellgewebe fettreich. Krankheit: Hämorr. Syphilis. Das Fett ist bei $15^{\circ} \mathrm{klarflüssig}$ und von hellgelber Farbe.

Fett V: 66jähriger Mann, Unterhautzellgewebe fettreich. Krankheit: Arteriosklerose. Das Fett ist bei $15^{0}$ dickflüssig, nur zum kleinen Theil fest und von blassgelber Farbe.

Fett VI: 70jährige Frau, starke Abmagerung. Krankheit: Starke Arteriosklerose. Das Fett ist bei $15^{\circ}$ fast ganz flüssig, nur sehr geringe, feste Abscheidung; Farbe orangegelb.

Fett VII: 45jährige Frau. Unterhautzellgewebe sehr fettreich. Krankheit: Lungenentzündung. Das Fett ist dickflüssig, nur zum kleinen Theil fest, von orangegelber Farbe.

Fett VIII: 3 Tage altes Kind. Das Fett ist fest, von blassgelber Farbe.

Fett IX: 2-3 Wochen altes Kind. Das Fett ist fest, von reinweisser Farbe.

\section{Lipomfette.}

Fett X: 43jährige Frau. Lipom der linken Schulter. Das Fett des Lipoms ist bei $15^{0}$ vollständig erstarrt, von hellgelber Farbe.

Fett XI: 52jähriger Mann. Lipom des Nackens. Das Fett ist bei $15^{\circ}$ ungefähr zur Hälfte fest, von kräftig gelber Farbe.

Fett XII: 40jähriger Mann. Sehr grosses Lipom des Oberarms. Das Fett ist bei $15^{\circ}$ vollständig erstarrt und von blassgelber Farbe.

Fett XIII: 50jähriger Mann. Kleines Lipom des Unterarms. Das Fett ist bei $15^{\circ}$ fest und von gelblichweisser Farbe.

Fett XIV: 48jährige Frau. Sehr grosses Lipom an der Innenseite der Mitte des Oberschenkels, mit Drucknekrose, Verjauchung und Verkalkung. Beginn des Lipoms vor 20 Jahren. 
Das Fett ist bei $15^{\circ}$ vollständig flüssig und von dunkelgelber Farbe.

Aus den centralen Partien dieses Lipoms, welche durch eine verkalkte Zone scharf von dem benachbarten Fettgewebe abgegrenzt waren, wurde ein Fett erhalten, das sich sowohl in seiner äusseren Beschaffenheit, als auch in seiner chemischen Zusammensetzung ausserordentlich von dem übrigen Fett des Lipoms unterschied. Dieses Fett war bei Zimmertemperatur zähflüssig und vollständig klar, von rotbrauner Farbe; es wird bei den nachfolgenden Analysenergebnissen als Fett XV angeführt werden, während als Fett XIV das aus dem äusseren Theil des Lipoms gewonnene Fett bezeichnet wird.

\section{Untersuchungsverfahren.}

1. Das specifische Gewicht wurde im Reischauerschen Pyknometer bei $15^{\circ}$ bestimmit und auf den luftleeren Raum reducirt.

2. Die Bestimmung des Lichtbrechungsvermögens erfolgte im Zeiss'schen Butterrefractometer bei $40^{\circ}$.

3. Die Verseifungszahl und 4. die Zahl der mit Wasserdampf flüchtigen Säuren (Reichert-Meissl'sche Zahl) wurden combinirt nach dem in der amtlichen Anweisung zur Untersuchung von Fetten und Oelen festgelegten Verfahren bestimmt.

5. Die Säurezahl wurde durch Titration der Fette in alkoholisch-ätherischer Lösung mit n/20 Alkali ermittelt. Aus ihr wurden die freien Fettsäuren als Oelsäure berechnet.

6. Die Jodzahl wurde nach v. Hübl bezw. nach der amtlichen Anweisung zur Untersuchung der Fette bestimmt. Dauer der Jodeinwirkung 6 Stunden.

7. Da über den Gehalt des Menschenfettes an unverseifbaren Bestandtheilen und höheren Alkoholen noch keine Daten vorliegen, wurde die Bestimmung derselben zur Erzielung genauer Zahlen jeweils mit möglichst viel Fett durchgeführt. Die grösste Menge stand bei Fett Nr. I zur Ver- 
fügung; es konnten daher in diesem Fall $400 \mathrm{~g}$ Fett zur Untersuchung der unverseifbaren Antheile verwendet werden. Das Fett wurde mit wässerig-alkoholischer Natronlauge verseift und die Seifenlösung 4 mal mit frisch destillirtem, leicht siedendem Petroläther ausgeschüttelt. Der beim Verdunsten des Petroläthers bleibende Rückstand wurde abermals mit wenig alkoholischer Lauge behandelt und wieder mit Petroläther aufgenommen. Um nun diese Petrolätherlösung möglichst von der gleichzeitig in kleinen Mengen darin gelösten Seife zu befreien, ${ }^{1}$ ) wurde sie mehrmals mit verdünnter, wässeriger Kalilauge ausgeschüttelt, mit Wasser wiederholt nachgewaschen und dann wieder abgedampft. Der Rückstand wurde mit gereinigtem Petroläther aufgenommen und die Lösung über Chlorcalcium getrocknet. Der Rückstand dieser filtrirten Petrolätherlösung wurde dann als «Unverseifbare Bestandtheile» zur Wägung gebracht. Als wichtigster Antheil war in diesen unverseifbaren Stoffen Cholesterin vorauszusetzen. Dieses wurde nach Boemer und Winter ${ }^{2}$ ) vermittelst Benzoylchlorid in den Benzoesäureester übergeführt und die Krystalle des letzteren durch Abschlemmen mit kaltem Alkohol von den übrigen unverseifbaren Stoffen getrennt. Durch Verseifung des Esters wurde der Alkohol zu seiner Identificirung wieder zurückgewonnen.

8. Zur Ermittelung des Lecithingehaltes der Fette waren die hierfür üblichen Verfahren nicht ohne Weiteres anwendbar. Der Gehalt des menschlichen Fettes an Lecithin bezw. an organisch gebundenem Phosphor ist normaler Weise so niedrig, dass zur Bestimmung dieses wichtigen und bisher noch nicht berücksichtigten Factors stets beträchtliche Mengen Fett in Angriff genommen werden mussten. Sowohl die directe Oxydation der Fette mit Kalihydrat und Salpeter, als auch das Verfahren nach Benedikt und Lewkowits $\mathrm{ch}^{3}$ ) brachte die Anwendung derart grosser Salzmengen

1) Vergl. Zeitschrift für angew. Chemie, 1898, 267.

2) Zeitschrift f. Untersuchung der Nahrungsmittel 1901, S. 865.

3) Benedikt-Ulzer, Analyse der Fette, 3. Aufl., S. 118. 
und dadurch eine so starke Verdünnung der schliesslich sich ergebenden Phosphatlösung mit sich, dass die Abscheidung der Phosphorsäure nicht mehr quantitativ erfolgen konnte. Auf die Einzelheiten der zur Beseitigung dieser Schwierigkeit nothwendigen, methodischen Vorarbeit, die an leichter zugängigem Material vorgenommen wurde, und ebenso auf die Begründung des gewählten Verfahrens an dieser Stelle einzugehen, würde zu weitläufig sein. Eine ausführlichere Mittheilung darüber wird demnächst in einer Arbeit über den Lecithingehalt der Fette erfolgen.

Es wurde schliesslich das Benedikt'sche Verfahren in folgender Weise abgeändert: Ungefähr $150 \mathrm{~g}$ Fett wurden in einem geräumigen Kolben geschmolzen und mit einer lauwarmen Lösung von $15 \mathrm{~g} \mathrm{NaOH}$ in $100 \mathrm{ccm} 70 \%$ igem Alkohol versetzt. Das Fett löste sich in wenigen Minuten klar auf. Diese Lösung wurde auf dem schwach siedenden Wasserbade stehen gelassen; bis auf Zusatz einiger Tropfen Phenolphtalein keine Röthung mehr eintrat. Alsdann wurden nochmals $100 \mathrm{ccm}$ obiger Lauge zugesetzt, und jetzt der Alkohol allmählich unter häufigem Umschütteln möglichst vollständig abgedunstet. Die Seife wurde mit heissem Wasser übergossen und dann etwas mehr Salpetersäure zugesetzt, als dem verwendeten Alkali entsprach. Nach der Zersetzung der Seife und der völligen Klärung der beiden Schichten wurde das Gefäss auf Eis gestellt und nach mehreren Stunden die wässerige, saure Lösung von den erstarrten Fettsäuren abgegossen. Die letzteren wurden in ähnlicher Weise in demselben Gefäss noch 3 mal mit Wasser sorgfältig nachgewaschen und die vereinigten wässerigen Lösungen nach dem Abstumpfen der freien Säure mit Natronlauge und nachfolgendem Zusatz von ungefähr einem Gramm krystallisirter Soda eingedampft. Der Rückstand musste zur Beseitigung des Glycerins zunächst einige Stunden vorsichtig über freier Flamme erhitzt werden; schliesslich wurde die Temperatur verstärkt, bis eine völlig farblose Schmelze erzielt war. In dieser Schmelze wurde jetzt nach dem Molybdänverfahren die Phosphorsäure bestimmt, wobei wieder zu berücksichtigen war, dass bei der Verseifung und auch durch 
die Oxydationsschmelze nicht unbeträchtliche Mengen von Kieselsäure aufgenommen worden waren.

Dass die in den Fetten gelösten, organischen Phosphorverbindungen thatsächlich Lecithine seien, konnte gleichfalls mit einiger Sicherheit erhärtet werden; wurden nämlich grössere Mengen Fett (200-300 g) mit schwach schwefelsäurehaltigem Wasser im Autoclaven unter einem Druck von 5-6 Atmosphären einige Stunden lang erhitzt, so konnte beim Uebersättigen des wässerigen Theils mit Kalilauge vermittelst Lakmuspapiers die Anwesenheit von flüchtigen Basen festgestellt werden. Auch trat hierbei der charakteristische Geruch der Alkylamine, wenn auch nur in sehr geringem Maasse, auf.

9. Zur Trennung und Bestimmung der Fettsäuren wurde ein Weg eingeschlagen, der in manchen Punkten nicht unwesentlich von den meist angewandten Verfahren abwich. Zunächst erfolgte die Bestimmung der isolirten Säuren nicht, wie allgemein üblich ist, durch die Analyse der Baryumsalze, sondern vermittelst der Silbersalze. Die Anwendung der letzteren bietet eine Reihe beachtenswerther Vortheile. Zunächst ist ihre Darstellung einfacher und sicherer, als die der Baryumsalze. Die Methode von F. Krafft ${ }^{1}$ ) zur Darstellung des Silberpalmitats kann, wie diesbezügliche Versuche sicher ergeben haben, auch für andere höhere Fettsäuren leicht angewendet werden. Dieselbe lässt sich überdies noch in folgender Weise vereinfachen: Man löst wenige Decigramme der Fettsäure in überschüssiger Ammoniaklösung und setzt hierzu eine hinreichende Menge nicht zu verdünnter (ungefähr $5 \%$ iger) Silbernitratlösung, welche gleichfalls vorher ammoniakalisch gemacht wurde. Tritt beim Vermischen der beiden Lösungen bereits die Abscheidung des fettsauren Silbers ein, so kann dieses mit wenigen Tropfen Ammoniakflüssigkeit wieder in Lösung gebracht werden. Zur Abscheidung des Silbersalzes wird die Lösung jetzt in soviel Wasser eingegossen, beziehentlich soweit verdünnt, bis die über dem beim Umrühren sich rasch zusammenballenden Niederschlag stehende

1) Nach Benedikt-Ulzer, Analyse der Fette, 3. Aufl., S. 12.

Hoppe-Seyler's Zeitschrift f. physiol. Chemie. XXXVI. 
Flüssigkeit auf weiteren Wasserzusatz vollkommen klar bleibt. Die Silbersalze werden nach dieser Methode in einer Form erhalten, in welcher sie sich äusserst leicht abfiltriren und auswaschen lassen. Das Auswaschen wurde nur so lange fortgesetzt, bis das Filtrat mit Salzsäure eben keine Reaction mehr gab. Nach dem Trocknen im Vacuumexsiccator unter Lichtabschluss wird eine abgewogene Menge des Salzes im Platintiegel verbrannt und das metallische Silber zur Wägung gebracht. Dass die Silbersalze der organischen Säuren viel leichter rein, d. i. frei von basischen oder sauren Salzen, darstellbar sind als die Baryumsalze, ist eine bekannte Thatsache. Ebenso unterliegen jene weniger leicht der hydrolytischen Zersetzung beim Auswaschen des Niederschlages. Die Silbersalze der höheren Fettsäuren können lange gewaschen werden, ehe nachweisbare Mengen von Silber in Lösung gehen. Schliesslich ist auch die Analyse der Silbersalze weit bequemer und sicherer, als die der Baryumsalze.

Die Arbeiten über die Darstellung der Silbersalze der Fettsüuren und ihre Verwendung zur Trennung der Fettsäuren werden fortgesetzt. Es mögen aber doch einige Analysen, die mit den sorgfältig gereinigten Säuren ausgeführt wurden, als Belege für die Genauigkeit des Verfahrens hier angeführt werden:

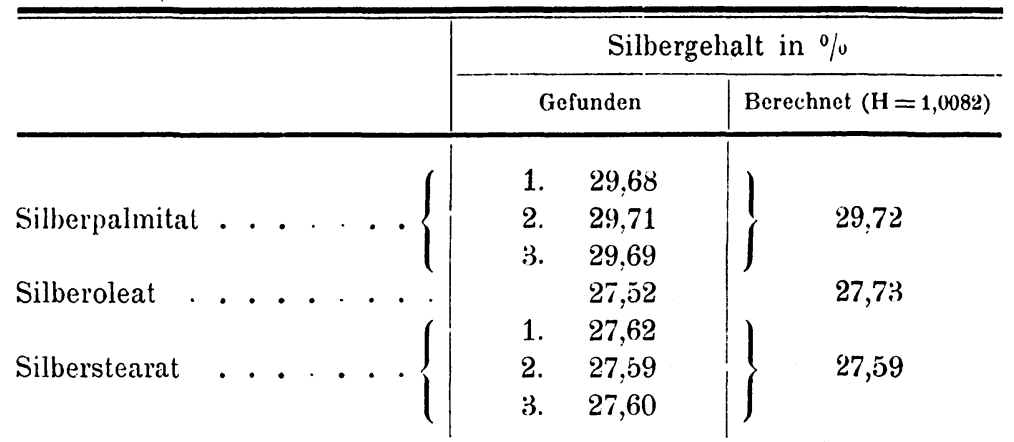

Auch die ausserordentliche Uebereinstimmung der zahlreichen, im Verlaufe der vorliegenden Arbeit ausgeführten Kontrollanalysen kann als beweisend dafür angesehen werden, dass die nach dieser Methode erhaltenen Werthe eine solche Annäherung an die berechneten Zahlen aufweisen, wie man 
sie mit den Baryumsalzen nur mehr oder weniger zufällig erhält.

Eine Frage ferner, welche vor Allem dringend der Klarstellung bedarf, ist die bezüglich der Trennung der flüssigen von den festen Fettsäuren. Die hierzu angewandten Verfahren - Modificationen der Methode von Varrentrapp ${ }^{1}$ ) - gründen auf der Thatsache, dass das ölsaure Blei leicht in Aether löslich ist, während das Lösungsvermögen des Aethers für die Bleisalze der gesättigten bezw. der festen Fettsäuren nach Lid off und anderen ein sehr geringes ist. Alle einschlägigen Methoden geben aber trotz dieser einwandsfreien Grundlage stets durchaus unbefriedigende Resultate. Während einerseits häufig zu viel feste Säuren gefunden werden, erhält man andererseits aus dem ätherlöslichen Theil der Bleisalze eine Oelsäure, deren Jodzahl viel zu niedrig ist. Der erstere Umstand wird meist dadurch erklärt, dass die compacten Bleisalze nicht genügend von dem Aether durchdrungen werden; der zweite dadurch, dass die Löslichkeit der Bleisalze der festen Säuren in Aether sich eben doch störend bemerkbar macht. Infolge dieser Schwierigkeiten hat Farnsteiner ${ }^{2}$ ) ein Verfahren vorgeschlagen, bei welchem statt Aether Benzol als Trennungsmittel der Bleisalze verwendet wird. Farnsteiner löst die gesammten Bleisalze in warmem Benzol auf und bringt durch Abkühlung der Lösung die Bleisalze der festen Fettsäuren wieder in krystallinischer Form zur Abscheidung. Die Lösung trennt Farnsteiner dann in sehr zweckmässiger Weise von dem Niederschlag und behandelt diesen noch 2 mal in gleicher Weise mit Benzol.

Da nun bei den vorliegenden Untersuchungen auf die Trennung und Bestimmung der in dem menschlichen Fett vorhandenen Fettsäuren ein besonderes Gewicht gelegt wurde, kamen das alte Verfahren von Varrentrapp nach der Muter-Koningh'schen Modification und die Benzolmethode Farnsteiner's vergleichsweise zur Anwendung. In den Fett-

1) Benedikt-Ulzer, Analyse der Fette etc., III. Aufl., S. $116 \mathrm{f}$.

2) Zeitschrift für Untersuchung der Nahrungsmittel 1898, S. 390. 
säuren eines Menschenfettes, welche nach der Jodzahl ces Fettes selbst $74 \%$ Oelsäure und nach der Jodzahl der Fettsäuren 74,1\% Oelsäure enthielten, wurde nach dem MuterKoningh'schen Verfahren 82,5\% Oelsäure gefunden. Diese "Oelsäure" hatte die Jodzahl 79,3, sie enthielt mithin rur $88,3 \%$ reine Oelsäure und $11,7 \%$ feste Säuren, entsprechend $72,85 \%$ Oelsäure der ursprünglichen Fettsäuren. (Die Voraussetzung, dass die Jodabsorption der Menschenfette und deren Fettsäuren nur durch die Anwesenheit der Oelsäure verursacht sei, wird im Folgenden noch begründet werden.) Diese unreine Oelsäure wurde nun nach dem Verfahren Farnsteiner's behandelt, und es gelang dadurch, aus ihr abermals 12,5\% feste Säuren $\mathrm{zu}$ isoliren. Von dem nach Muter-Koningh rnit $82,5 \%$ gefundenen Oelsäuregehalt der Fettsäuren sind mithin nochmals 10,3\% feste Säuren in Abzug zu bringen; der nach Farnsteiner gefundene Oelsäuregehalt der ursprünglichen Fettsäuren beträgt demnach $72,2 \%$. Die hierbei erhaltene Oelsäure zeigte bereits die Jodzahl 82,8. Die theoretische Jodzahl der Oelsäure beträgt $89,84(\mathrm{H}=1,01, \mathrm{~J}=126,85)$. Nach der bereits angeführten Methode wurde das Silbersalz dieser Oelsäure dargestellt. Es enthielt 27,31\% Ag. (Silberoleat $=27,73 \% \mathrm{Ag}$ ). Die noch zu niedrige Jodzahl sowie der Silbergehalt des Salzes, welcher bereits unter den der Oelsäure gesunken war, erklären sich durch die bei der mannigfachen Behandlung der Oelsäure unvermeidliche Bildung von Oxyölsäure. Es lieferten nämlich die nach F arnsteiner's Methode aus der rohen Oelsäure isolirten festen Säuren ein Silbersalz, das einen Silbergehalt von $29,04 \%$ hatte. Falls noch beträchtlichere Mengen dieser festen Säuren in der Oelsäure nach ihrer Reinigung mit Benzol vorhanden gewesen wären, hätte der Silbergehalt des Oleats höher sein müssen, als er gefunden wurde.

Aus diesem Ergebniss, vor Allem aus dem Umstand, dass aus der nach Muter-Koningh gewonnenen Oelsäure vermittelst des Benzolverfahrens neuerdings solche Mengen fester Säuren isolirt werden konnten, darf doch wohl mit Sicherheit abgeleitet werden, dass das Verfahren Farnsteiner's den 
älteren Verfahren weit überlegen ist. ${ }^{1}$ ) Es verdient gewiss eine grössere Beachtung als die, welche es bisher namentlich ausserhalb des Kreises der speciellen analytischen Chemie gefunden hat. Auch darf hier ausgesprochen werden, dass alle Zahlen über das Verhältniss der flüssigen und festen Säuren, die auf Grund der Löslichkeit der Bleisalze im Aether gewonnen sind, nur zufällig den wirklichen Verhältnissen entsprechen können. Die Fehler, welche alle auf dieser Grundlage aufgebauten Methoden geben können, sind viel grösser, als dass man sie noch als sogenannte Methodenfehler in den Kauf nehmen dürfte.

Bemerkenswerth ist noch, dass die Löslichkeit des Bleipalmitats und -Stearats in Aether eine ungleich grössere ist bei Anwesenheit von Bleioleat, als sie für die betreffenden Salze allein in dem [ösungsmittel festgestellt wurde. ${ }^{2}$ ) Diese Erscheinung erklärt sich leicht durch die Annahme, dass nach dem Vertheilungsgesetz bei der Bildung der Salze dieser höheren Fettsäuren mit einer Base neben den jeweiligen reinen Salzen auch eine bestimmte Menge gemischter Salze sich bildet; die Mischung der Bleisalze enthielte dann neben den einfachen Salzen $\mathrm{Blei}$ / oleat oleat Blei $\backslash_{\text {stearat }}^{\text {stearat }}$ und Blei $/$ palmitat

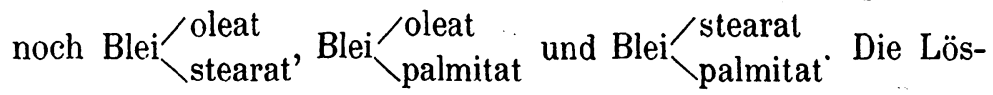
lichkeit dieser gemischten Salze in einem nicht dissociirenden Lösungsmittel müsste dann auch zur Löslichkeit der normalen Salze in einem abweichenden Verhältniss stehen. Diese Erklärung dürtte befriedigender sein, als die gemeinhin gegebene, dass die Löslichkeit des Salzes A durch die Anwesenheit des Salzes B in dem Lösungsmittel erhöht werde, eine Erklärung, welche ihrerseits wieder eine zweite Erklärung nöthig macht. Die Annahme der Bildung gemischter Salze würde ausserdem noch dem Umstand Rechnung tragen, dass man selbst bei sorgfältigster Vermeidung der Bildung

1) Vergl. Lunge, chem.-techn. Untersuchungsmethoden, III, S. 116.

2) Benedikt-Ulzer, Analyse der Fette, III, S. 166. 
basischer oder saurer Salze nach den in Frage stehenden Verfahren unbefriedigende Resultate erhält.

Die Prüfung der Fettsäuren auf einen Gehalt an höher ungesättigten Fettsäuren (Säure der Linol- und Linolensäurereihe) erfolgte gleichfalls nach einem Vorschlag Farnsteiner's ${ }^{1}$ ) durch Behandeln der Baryumsalze der Fettsäuren mit alkoholhaltigem Benzol. Das Löslichkeitsverhältniss dieser Salze sowie die Jodzahl der Oelsäure liessen die Anwesenheit von höher ungesättigten Säuren ausgeschlossen erscheinen. Es war in Folge dessen statthaft, aus der Jodzahl der Fette unmittelbar den Gehalt an Oelsäure zu berechnen.

Die Untersuchung der festen Fettsäuren erfolgte derart, dass die nach Farnsteiner's Verfahren unter Wasserstoff von Oleat befreiten Bleisalze in heissem Benzol gelöst und diese Lösung mit verdünnter Schwefelsäure zerlegt wurde. Von den nach dem Abdampfen des Benzols erhaltenen Fettsäuren wurde ein kleiner Theil direct in die Silbersalze übergeführt und diese analysirt. Der übrige Theil der Säuren wurde der fractionirten Krystallisation aus Alkohol unterworfen und die Silbersalze der einzelnen Fractionen in derselben Weise analysirt.

Obgleich in einigen Fällen diese fractionirte Krystallisation der Säuren fast überflüssig weit ausgedehnt worden war - bei Fett Nr. 1 wurden 22 Fractionen dargestellt konnte doch kein einziges Mal ein Silbersalz erhalten werden, dessen Silbergehalt grösser als der des Palmitats oder kleiner als der des Stearats gewesen wäre. Die Anwesenheit anderer fester Säuren als Palmitinsäure und Stearinsäure wurde mithin so unwahrscheinlich, dass ohne Gefahr eines wesentlichen Irrthums aus dem Silbergehalt der Salze ihr Procentgehalt an Palmitinsäure und Stearinsäure berechnet werden konnte.

Der Nachweis der niedrigeren Glieder der Essigsäurereihe wurde bei Fett I combinirt mit der Bestimmung des Cholesterins durchgeführt.

1) Zeitschrift für Untersuchung der Nahrungsmittel 1899, 1. 
Die Seife von $400 \mathrm{~g}$ Fett wurde aus der wässerigen Lösung mit Kochsalz abgeschieden, die Unterlauge mit Schwefelsäure übersättigt und mit Aether ausgeschüttelt. Es konnten in dem Aetherrückstand die Fettsäuren der Essigsäurereihe von der Laurinsäure abwärts erwartet werden. Die hierbei als Nebenproduct erhaltene Seife wurde zur Trennung der höheren Fettsäuren verwendet. Sie wurde hierzu in heissem Alkohol gelöst und die filtrirte Lösung unter fortwährendem Umschütteln abgekühlt. Dadurch konnte das Gelatiniren der gesättigten Seifenlösung verhindert werden; die Seife schied sich vielmehr in Form von Fäden ab, von welchen sehr bequem abfiltrirt werden konnte.

Bei der Verarbeitung grosser Fettmengen hat sich diese erste Trennung der Seifen durch fractionirte Abscheidung derselben gut bewährt; die ersten Fractionen bestanden grösstentheils aus den Salzen der festen Fettsäuren, aus welchen diese sehr leicht rein erhalten werden konnten.

Untersuchungsergebniss.

(Siehe I. und II. auf Seite 112 und 113.)

Das specifische Gewicht wurde nur bei Fett Nr. 1 bestimmt. Es betrug hier 0,9179.

Das Lichtbrechungsvermögen der Unterhautfette von Erwachsenen schwankt zwischen 50,2-52,3 Scalentheilen, das der Lipomfette zwischen 49,6-53,1. (Es darf hier bemerkt werden, dass Fett XV bei diesem Vergleich der Lipomfette mit dem Normalfett nicht berücksichtigt wird, da dieses Fett in Folge der tiefgreifenden pathologischen Veränderungen des Gewebes, aus welchem dasselbe stammt, als höchst abnorm angesehen werden muss.) Die beiden Kinderfette dagegen zeigen ein beträchtlich niedrigeres Lichtbrechungsvermögen, nämlich 47 bezw. 48,8 Scalentheile. Diese Differenz zwischen dem Lichtbrechungsvermögen der Fette von Erwachsenen und dem der Kinderfette steht im Zusammenhang mit dem Oelsäuregehalt der Fette. Nach der tabellarischen Zusammenstellung zeigen die Analysenergebnisse eine fast ausnahmslose Gesetzmässigkeit zwischen dem Lichtbrechungsvermögen und dem Oelsäuregehalt 
Hermann Jaeckle.

\begin{tabular}{|c|c|c|c|c|c|}
\hline 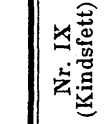 & $\stackrel{\vec{w}}{\underline{w}}$ & 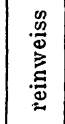 & 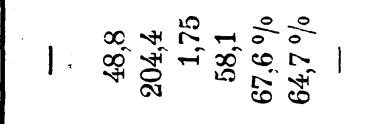 & 11111 & 11 \\
\hline 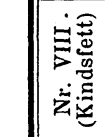 & $\stackrel{\vec{g}}{\underline{d}}$ & 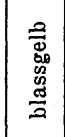 & 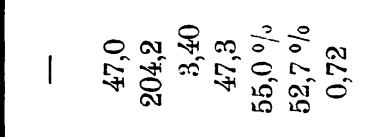 & 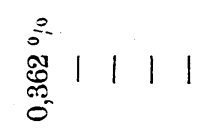 & 11 \\
\hline $\begin{array}{l}\text { 空 } \\
\text { 芸 }\end{array}$ & 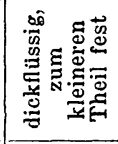 & 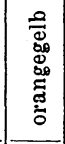 & 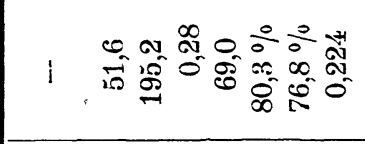 & 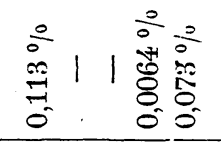 & 11 \\
\hline $\begin{array}{l}\overrightarrow{>} \\
\dot{\mathrm{z}}\end{array}$ & 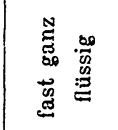 & 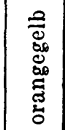 & 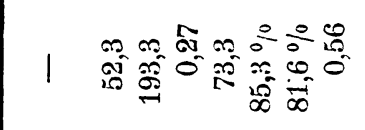 &${ \underset{ \underset {\substack{ \substack {\circ{ \circ \\
\multirow{2}{N}\\
{{c}{0 \\
0}}}\end{subarray}}{ } \mid}$ & 1 \\
\hline 离 & 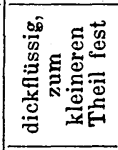 & 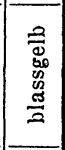 & 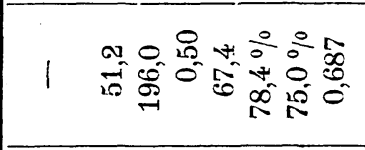 & $\begin{array}{l}2 \\
0 \\
0 \\
0 \\
0 \\
0\end{array}$ & 11 \\
\hline $\begin{array}{l}\vec{z} \\
\dot{\vec{z}}\end{array}$ & 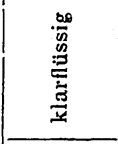 & 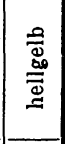 & 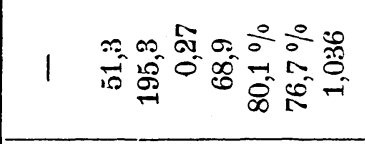 & 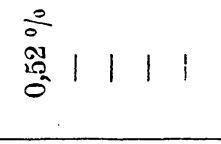 & 11 \\
\hline$\Xi$ & 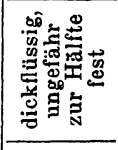 & 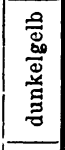 & 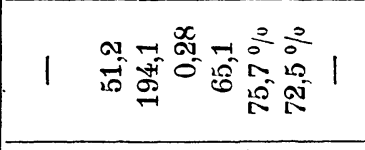 & 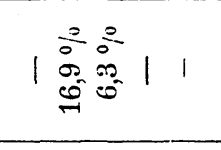 & 11 \\
\hline$\Xi$ & 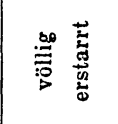 & 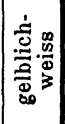 & 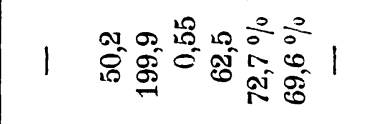 & 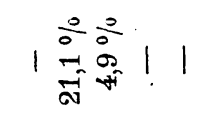 & 11 \\
\hline 芸 & 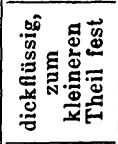 & 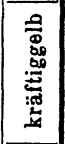 & 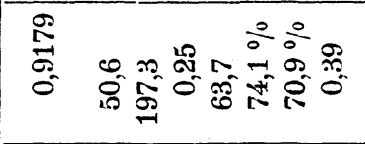 & 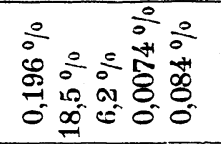 & 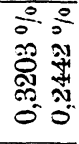 \\
\hline & 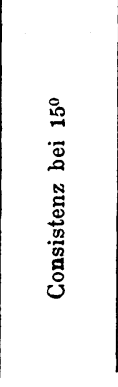 & 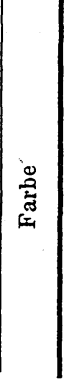 & 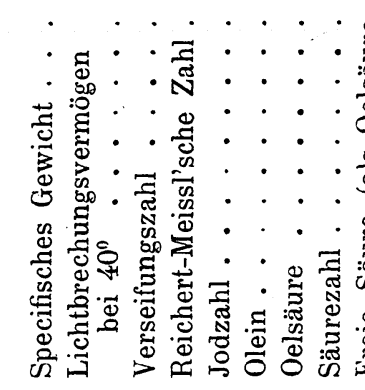 & 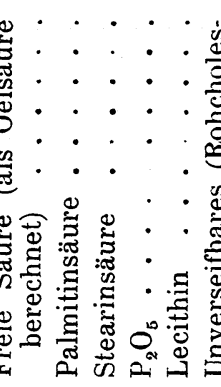 & 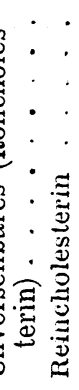 \\
\hline
\end{tabular}


Ueber die Zusammensetzung des menschlichen Fettes.

\begin{tabular}{|c|c|c|c|}
\hline $\begin{array}{l}\bar{z} \\
\dot{\vec{\Delta}}\end{array}$ & 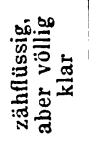 & 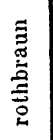 & 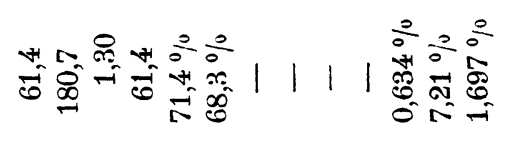 \\
\hline $\begin{array}{l}\overrightarrow{z^{\prime}} \\
\dot{\vec{z}}\end{array}$ & 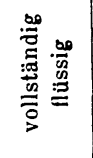 & 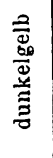 & 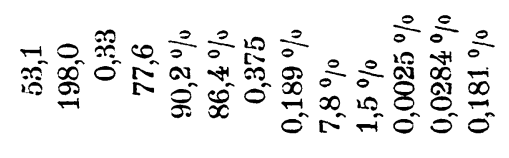 \\
\hline $\mid \begin{array}{l}\vec{z} \\
\dot{\vec{z}} \\
\dot{z}\end{array}$ & 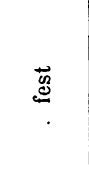 & 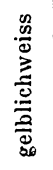 & 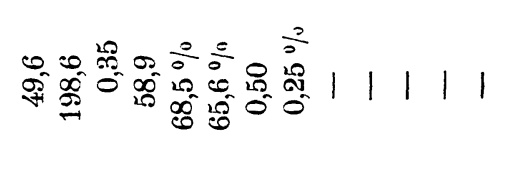 \\
\hline $\begin{array}{l}\overrightarrow{y^{\prime}} \\
\dot{\vec{z}}\end{array}$ & 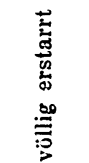 & 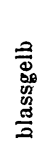 & 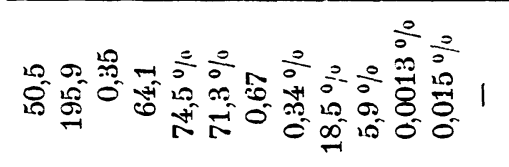 \\
\hline $\begin{array}{l}\overrightarrow{\bar{z}} \\
\dot{\vec{z}}\end{array}$ & 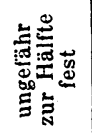 & 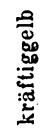 & 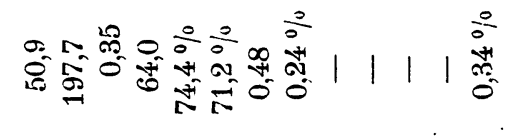 \\
\hline $\begin{array}{l}\dot{4} \\
\dot{z}\end{array}$ & 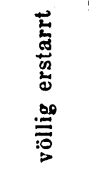 & 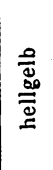 & 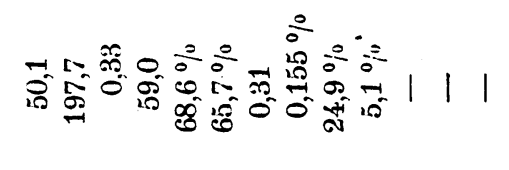 \\
\hline & 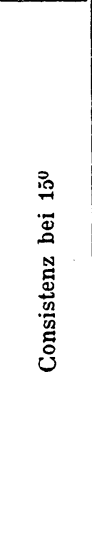 & 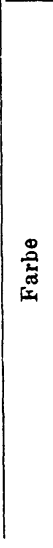 & 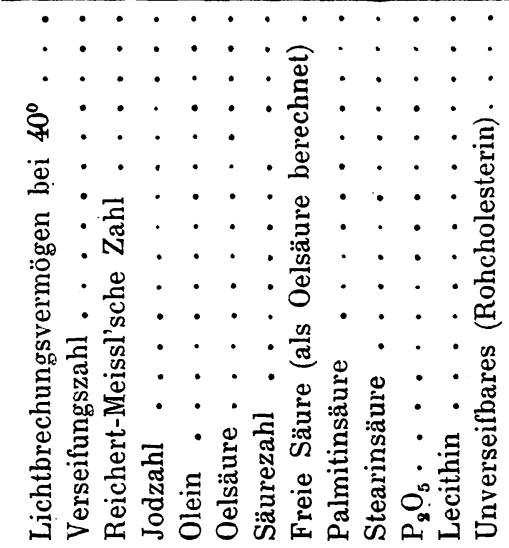 \\
\hline
\end{tabular}


bezw. der Jodzahl. Es bestätigt sich hierdurch die Erfahrung, dass das Lichtbrechungsvermögen im Allgemeinen der Jodzahl proportional ist, auch für das menschliche Fett.

Die Verseifungszahlen der Unterhautfette bewegen sich zwischen 193,3 und 199,9, die der Lipomfette zwischen 195,9 und 198,8 .

Während hier kein nennenswerther Unterschied zu constatiren ist, zeigen die Kinderfette bedeutend höhere Verseifungszahlen, nämlich 204,3 und 204,4. Es ist demnach in den Kinderfetten die Anwesenheit von Fettsäuren mit kleinerem Molekulargewicht vorauszusetzen.

Die Reichert-Meissl'schen Zahlen sind bei den Unterhautfetten $(0,25-0,55)$ und den Lipomfetten $(0,33-0,35)$ gleich niedrig. Sie stehen an der untersten Grenze der Zahlenreihe, welche für die Säugethierfette nachgewiesen ist. Der Gehalt des Fettes vom erwachsenen Menschen an mit $W$ asserdampf flüchtigen Säuren kann mithin nur ein äusserst kleiner sein.

Dieser Befund wurde auch bestätigt durch das in Folgendem angeführte Ergebniss der Trennung der Fettsäuren. Es wird daher später auf diese Frage zurückzukommen sein.

Im Gegensatz zu den Fetten von Erwachsenen zeigen die Kinderfette auffallend hohe Reichert-Meissl'sche Zahlen. Im ursächlichen Zusammenhang damit stehen die erwähnten hohen Verseifungszahlen der Kinderfette.

Der beträchtliche Gehalt der Kinderfette an niedrigen Fettsäuren ist auch einer der bemerkenswerthesten Unterschiede zwischen dem Fett des Erwachsenen und dem Kinderfett. Das Fett eines 3 Tage alten Kindes (Fett VIII) hatte die ReichertMeissl'sche Zahl 3,4, das eines 2-3 Wochen alten Kindes die Reichert-Meis sl'sche Zahl 1,75. Die Menge der niedrigen Fettsäuren ist demnach dem Lebensalter umgekehrt proportional. Vor Allem weisen diese hohen Reichert-Meissl'schen Zahlen und ebenso die Verseifungszahlen auf die beachtenswerthe Thatsache hin, dass das Fett des Neugeborenen sich in seiner Zusammensetzung dem Milchfett ausserordentlich nähert, und dass der Uebergang zur Zusammensetzung 
des Fettes der Erwachsenen sehr frühzeitig einzutreten scheint. Mangels diesbezïglichen Materials konnte diese Frage nicht verfolgt werden. Eine nähere Untersuchung dieser Verhältnisse an den Fetten von Neugeborenen, von Säuglingen sowie von künstlich ernährten Kindern verschiedenen Alters dürfte in mancher Beziehung werthvolle Aufschlüsse $\mathrm{zu}$ geben im Stande sein.

Die Säurezahlen der Unterhautfette betragen $0,22-1,04$, die der Lipomfette $0,31-0,67$, die des Kinderfettes VIII 0,72. Daraus berechnet sich der Gehalt an freien Fettsäuren (als Oelsäure angenommen) bei den Unterhautfetten mit $0,113-0,52 \%$, bei den Lipomfetten mit $0,155-0,34 \%$ und bei dem Kinderfett VIII mit $0,362 \%$. Diese Ergebnisse stehen im Widerspruch mit den Angaben von Schulz und Schwalbach, sowie von Mitchell. Der ausserordentlich hohe Gehalt $(7,31 \%)$ an freier Säure, welchen Schulz und Schwalbach in ihrem Lipomfett gefunden haben, kennzeichnet das letztere als einen aussergewöhnlichen Fall, wenn man nicht etwa die Ursache für die ausserordentlich hohe Acidität dieses Fettes darin finden will, dass das betreffende Lipom vor der Untersuchung 14 Tage lang in $40 \%$ igem Alkohol aufbewahrt wurde.

Ruppel fand in dem Fett eines Lipoms 1\% freie Fettsäuren, während Mitchell in dem von ihm untersuchten Fett die Säurezahl 6,3, entsprechend 3,17\% freier Säure (als Oelsäure berechnet) fand.

Auch Lindemann ${ }^{1}$ ) fand für ein Unterhautfett die hohe Säurezahl 3,76, entsprechend 1,89\% freier Oelsäure. Auf der anderen Seite aber hat Hofmann, wie bereits erwähnt, in zwei Fetten einen noch niedrigeren Säuregehalt $(0,003$ und $0,062 \%$, als $\mathrm{H}_{2} \mathrm{SO}_{4}$ berechnet, entsprechend 0,0043 und $0,089 \%$ Oelsäure) gefunden, als der Durchschnitt der vorliegenden Analysen beträgt. Nach der Annahme, dass das normale Fett im Körper selbst neutral ist, $\left.{ }^{2}\right)$ muss der Säuregehalt des

1) Zeitschrift für Biologie, Bd. 38, S. 405; nach Virchow's Jahresberichten, Bd. 34, S. 1, 117.

2) Vergl. u. A. Bunge, Physiologische Chemie, III. Aufl., S. 201. 
zur Untersuchung gelangenden Fettes lediglich von der Gewinnung des Fettes aus dem Gewebe herrühren und mithin in erster Linie von der Art der Gewinnung abhängig sein. Mit Rücksicht auf die bekannte Thatsache, dass der Säuregehalt der Fette mit der Aufbewahrung derselben regelmässig ansteigt, wurde die Mehrzahl der Fette unmittelbar nach dem Ausschmelzen titrirt. Es wurden aber auch in diesen Fällen innerhalb derselben Grenzen sich bewegende Säurezahlen erhalten wie in den Fetten, welche erst nach mehrtägigem Stehen unter Luft- und Lichtabschluss zur Untersuchung gelangten. Die Differenzen zwischen den Befunden der verschiedenen Autoren können daher auf die verschiedene Gewinnung der Fette und vielleicht auch auf die Art der Titration zurückgeführt werden.

Die Jodzahlen der Fette zeigen dieselben beträchtlichen Schwankungen, wie sie für die anderen Säugethierfette seit langem bekannt sind. Bei den Unterhautfetten betragen die Jodzahlen 62,5-73,3, bei den Lipomfetten 58,9-76,6; die Kinderfette dagegen haben die Jodzahlen 47,3 und 58,1.

Da die Jodzahl bei den menschlichen Fetten den Gehalt an Oelsäure zum Ausdruck bringt, so wird die nähere Besprechung dieser Verhältnisse bei dem Capitel "Fettsäuren » erfolgen.

Der Gehalt an unverseifbaren Bestandtheilen beträgt bei dem Unterhautfett I $0,3203 \%$, davon waren $0,2442 \%$ reines Cholesterin.

Ausserdem enthielten diese unverseifbaren Bestandtheile den Farbstoff des Fettes in Form von rothen, öligen Tropfen. Das Cholesterin zeigte nach der Reinigung über den Benzoesäureester den Schmelzpunkt $146-147^{\circ}$ und gab die Salkowski'sche Reaction. Es charakterisirte sich hierdurch als das gewöhnliche, thierische Cholesterin.

Die Versuche zur Ermittelung der chemischen Natur des Farbstoffs blieben bei der äusserst geringen Menge, in welcher dieser in den Fetten vorhanden ist, ergebnisslos. Es konnte nur festgestellt werden, dass der Fettfarbstoff die Reaction der Gallenfarbstoffe nicht gab. Es dürfte mithin 
wohl das Nächstliegende sein, ihn in die Klasse der Lipochrome einzureihen.

Der Gehalt der Lipomfette an unverseifbaren Bestandtheilen wurde in zwei Fällen bestimmt. Er betrug bei dem Fett XI $0,34 \%$ und bei dem Fett XIV 0,181\%.

Aus der letzteren Zahl kann ein Unterschied zwischen dem Cholesteringehalt der Unterhautfette und dem der Lipomfette nicht abgeleitet werden, da die Zusammensetzung des Fettes XIV bereits durch die secundären pathologischen Processe innerhalb des betreffenden Lipoms beeinflusst sein kann. Bei der am Schluss angefügten Besprechung des Fettes XV aus dem innersten Theil desselben Lipoms wird hierauf zurückzukommen sein.

Ueber den Gehalt des menschlichen Fettes an Lecithin liegen bis jetzt in der Litteratur noch keine Zahlen vor. Es stand nur in wenigen Fällen eine solche Menge des Fettes zur Verfügung, dass der Lecithingehalt desselben quantitativ bestimmt werden konnte. Fett Nr. 1 enthielt $0,084 \%$ Lecithin, Fett Nr. VII 0,073\% \% Die Lipomfette Nr. XII und Nr. XIV dagegen enthielten nur $0,015 \%$ und $0,0284 \%$ Lecithin.

Der Lecithingehalt der Unterhautfette ist verhältnissmässig hoch. Es wurde im Laufe dieses Jahres der Lecithingehalt einer grossen Anzahl von Fetten bestimmt, und es konnte hierbei kein animalisches Fett mit demselben oder mit höherem Lecithingehalt beobachtet werden. Immerhin soll aber diesem Umstand in Anbetracht des durchweg sehr niedrigen Gehaltes der Säugethierfette an Lecithin kein besonderes Gewicht beigemessen werden.

Ausserdem zeigt sich in dem Gehalt an Lecithin zum ersten Mal ein Unterschied zwischen dem Unterhautfett und dem Lipomfett. Der Lecithingehalt der Lipomfette beträgt durchschnittlich nur den 4. Theil des Lecithingehaltes der Unterhautfette. Weil aber mit den individuellen Schwankungen in der Zusammensetzung dieser jeweils von verschiedenen Personen stammenden Fette gerechnet werden musste, war es von Interesse, den Lecithingehalt des Unterhautfettes und Lipomfettes von ein und demselben Individuum zu untersuchen. Da 
während der Niederschrift dieser Arbeit entsprechendes Material zur Verfügıng stand, wurde dieses noch nachträglich in die Untersuchung hineingezogen; die Analysendaten sind in die Tabelle nicht aufgenommen worden. Das Unterhautfett enthielt in diesem Falle 0,0077\% $\mathrm{P}_{2} \mathrm{O}_{5}$, entsprechend 0,088\% Lecithin; das Fett des Lipoms 0,0084\% $\mathrm{P}_{z} \mathrm{O}_{5}$, entsprechend $0,095 \%$ Lecithin. Die Erwartung, dass der Lecithingehalt des Lipomfettes niedriger sein würde als der des Unterhautfettes, hatte sich demnach nicht bestätigt. Es ist aber hier zu berücksichtigen, dass es sich in diesem Falle um ein sehr kleines Lipom (annäherndes Gewicht $1.50 \mathrm{~g}$ ) handelte, während die Lipomfette XII und XIV aus ausserordentlich grossen Lipomen stammten. Es bleibt mithin doch noch die Möglichkeit bestehen, dass durch die locale Anhäufung sehr grosser Fettmengen in den Lipomen der Lecithingehalt des Fettes herabgesetzt wird. Da indessen die Lecithinverhältnisse in dem Lipom, aus welchem Fett XIV und XV gewonnen wurden, für die Beurtheilung dieser Frage von Werth sind, darf diese bis zur Besprechung des Fettes XV zurückgelegt werden.

Die Ermittelung der in den Fetten vorhandenen Säuren förderte sehr einfache Verhältnisse zu Tage. Neben der Oelsäure konnte nur Palmitinsäure und Stearinsäure mit Sicherheit nachgewiesen werden. Als Grenzwerthe bei der Analyse der Silbersalze der festen Säuren wurden der Silbergehalt des Palmitats $(29,71 \% \mathrm{Ag}$, berechnet $29,72 \%)$ und der des Stearates $(27,59 \%$, berechnet $27,59 \%)$ erhalten. Die sehr grosse Anzahl der übrigen analysirten Silbersalze ergab ausnahmslos dazwischen liegende Werthe. Es sind für das Fett der Erwachsenen und das Lipomfett demnach Säuren mit höherem Molekulargewicht als das der Stearinsäure und ebenso auch die Glieder der Essigsäurereihe von der Palmitinsäure abwärts bis zur Laurinsäure auszuschliessen.

Bei der Isolirung der niedrigsten Glieder der Essigsäurereihe aus den Fetten von Erwachsenen wurden erst bei der Anwendung beträchtlicher Fettmengen (400 g) einige Centigramme von niedrigen Fettsäuren erhalten, die auf wenig Wasser zunächst in öligen Tröpfchen schwammen, sich beim 
Umrühren in einigen Tropfen Wasser aber leicht aufösten. Diese Lösung gab weder mit Baryumhydratlösung noch mit Silbernitratlösung einen Niederschlag. Dieses Verhalten sowie der Geruch deuteten mit einiger Wahrscheinlichkeit auf Buttersäure hin. Eine Analyse war bei der kleinen Quantität nicht durchführbar.

Da ferner aus der Klasse der ungesättigten Säuren nur 0 elsäure nachgewiesen werden konnte, besteht mithin das Unterhautfett der Erwachsenen und ebenso das Lipomfett so gut wie ausschliesslich aus den Glyceriden der Oelsäure, Palmitinsäure und Stearinsäure. Von diesen überwiegt stets weitaus das Olein; dasselbe beträgt bei den Unterhautfetten 72,7-85,2\%, entsprechend 69,6-81,6\% Oelsäure, bei den Lipomfetten 68,5-90,2\%, entsprechend 65,6-86,4\% Oelsäure.

Der Gehalt des menschlichen Fettes an Oelsäure ist mithin ein sehr schwankender; ein wesentlicher Unterschied zwischen den Unterhautfetten und den Lipomfetten tritt hier nicht zu Tage. Den Höchstgehalt wies Fett Nr. XIV auf; dieses bestand zu $9 / 10$ aus Olein.

Bemerkenswerth ist hierbei noch der Umstand, dass ausser der Consistenz auch die Farbe der Fette in einem streng regelmässigen Verhältniss zum Oelsäuregehalt stand. Je höher der Oelsäuregehalt, um so dunkler gefärbt ist das Fett.

Nach der Oelsäure ist stets die Palmitinsäure in grösster Menge vorhanden, während die Stearinsäure in allen Fällen hinter der Palmitinsäure ganz beträchtlich zurücktritt. Das Verhältniss der Palmitinsäure zur Stearinsäure ist ein wechselndes; es bewegt sich zwischen $3: 1$ und $\tilde{z}: 1$. Dieser Befund bestätigt die Angaben von Schulz und Schwalbach sowie von Ruppel nicht: Nach den Analysenbefunden dieser Autoren bei Lipomfetten würde ein wesentlicher Unterschied zwischen dem Lipomfett und dem Fett aus dem Unterhautzellgewebe darin liegen, dass im Lipomfett die Stearinsäure die in weitaus grösster Menge vorhandene feste Fettsäure ist, während im Unterhautfett stets der Palmitinsäure diese Rolle zukommt. In Folge dieser Differenz wurde auf die Klarlegung eben dieser Frage besondere Sorgfalt ver- 
wendet. Es konnte in sechs Fällen - in drei Unterhautfetten und drei Lipomfetten - stets dasselbe bedeutende Ueberwiegen der Palmitinsäure constatirt werden. Das Lipomfett deckt sich also auch in diesem Punkte völlig mit dem Normalfett.

In den Kinderfetten dagegen treten die Fettsäuren in einem wesentlich anderen Verhältniss auf. Dass hier vor Allem die niedrigeren Glieder der Essigsäurereihe in weit grösseren Mengen vorhanden sind, wurde schon bei der Besprechung der Reichert-Meissl'schen Zahlen dargethan. Der Gehalt an Olein beträgt bei dem Fett VIII (3 Tage altes Kind) nur $55,0 \%$, entsprechend $52,7 \%$ Oelsäure, bei dem Fett IX (2-3 Wochen altes Kind) 67,6\%, entsprechend $64,7 \%$ Oelsäure. Der Oelsäuregehalt ist demnach in dem zweiten Fett bereits nach wenigen Wochen dem des Fettes von Erwachsenen sehr nahe gerückt.

Es war noch die Frage offen, ob diese in dem menschlichen Fett nachgewiesenen Säuren darin in Form von einfachen oder von gemischten Estern vorliegen: Der Rest des Unterhautfettes Nr. I wurde zunächst mehrere Tage im Eisschrank bei $+3^{0}$ stehen gelassen, dann auf Thonplatten von derselben Temperatur gestrichen und wieder einige Tage im mit Kohlensäure gefüllten Exsiccator kalt gestellt. Hierauf wurde der feste Antheil von den Thonplatten abgenommen und aus Alkoholäther wiederholt umkrystallisirt. Die Ester wurden so in Form von reinweissen, strahligbüscheligen Krystallen erhalten. Ihr Jodabsorptionsvermögen war so gut wie Null, sie enthielten demnach keine Oelsäure. Es konnte sich also nur um einfache oder gemischte Ester der Palmitinund Stearinsäure handeln.

Die Ester wurden nun durch Krystallisation in eine Anzahl von Fractionen zerlegt, diese verseift, die Säuren in Form der Silbersalze ausgefällt und diese analysirt. Der Silbergehalt bewegte sich ohne jede Gesetzmässigkeit zwischen dem des Silberpalmitats und -stearats. Es ist demnach sehr unwahrscheinlich, dass in dem menschlichen Fett neben dem Triolein, Tripalmitin und Tristearin noch gemischte Ester der drei Fettsäuren vorhanden sind. 
Auch die Frage nach dem Einfluss des Ernährungszustandes des Individuums auf die Zusammensetzung des Fettes ist noch kurz zu berühren. Dieser müsste sich in erster Linie in einer Aenderung des Mischungsverhältnisses der drei Ester bemerkbar machen. Fett II und I sind die ölsäureärmsten der Unterhautfette; Fett I stammt von einer sehr fettreichen Person, Fett II von einer fettarmen. Dasselbe ist der Fall bei den beiden ölsäurereichsten der Unterhautfette, Fett VI und Fett VII. Es ist demnach nicht wahrscheinlich, dass die Zusammensetzung des Fettes vom Ernährungszustand des Menschen wesentlich abhängig ist; die Schwankungen in der Zusammensetzung können vielmehr als rein individuelle angesehen werden.

Der naheliegende Vergleich des menschlichen Fettes mit den andern Säugethierfetten erledigt sich nach dem bisher Mitgetheilten in einfacher Weise: Es konnte weder eine dem menschlichen Fett eigenthümliche Säure oder ein anderer charakteristischer Bestandtheil, noch ein bemerkenswerthes Hervortreten oder Fehlen irgend eines der normalen Bestandtheile der Fette beobachtet werden. Das menschliche Fett zeigt mithin in seiner chemischen Zusammensetzung kein Unterscheidungsmerkmal gegenüber den Fetten der übrigen höheren Säugethiere.

Zum Schluss erübrigt noch die Besprechung des Fettes $\mathrm{Nr}$. XV, d. i. desjenigen Fettes, welches aus dem durch eine verkalkte Schicht von dem übrigen Fettgewebe scharf abgegrenzten, centralen Theil desselben Lipoms erhalten wurde, aus dessen äusserem Theil das Fett XIV stammt.

Dieses Fett wich, wie bereits erwähnt, in seiner äusseren Beschaffenheit von allen übrigen Lipomfetten, und damit auch von dem Fett aus dem äusseren Theil desselben Lipoms, ganz beträchtlich ab. Es war zähflüssig und von rothbrauner Farbe; auch bei starker Abkühlung blieb es vollkommen klar. Die Analysenresultate zeigen durchweg andere Verhältnisse: Das Lichtbrechungsvermögen ist sehr hoch $(61,4$ Scalentheile):

Hoppe-Seyler's Zeitschrift f. physiol. Chemie. XXXVI. 
Trotz der auffallend niedrigen Verseifungszahl (180,7) zeigt das Fett eine verhältnissmässig hohe Reichert-Meissl'sche Zahl. Das Fett muss demnach neben den niedrigen Säuren noch Säuren mit sehr hohem Molekulargewicht enthalten. Interessant ist vor Allem aber der Gehalt des Fettes an Cholesterin und Lecithin. Der Gehalt des Fettes an unverseifbaren Antheilen beträgt 1,697\%/0; diese bestanden fast ganz aus Cholesterin. Der Cholesteringehalt ist daher ungefähr 5-6 mal höher als in den normalen Fetten.

Ferner enthält das Fett XV 7,21\% Lecithin, d. i. rund das 100 fache des Lecithingehaltes der Unterhautfette.

Da nun ein ursächlicher Zusammenhang dieser ausserordentlichen Anreicherung von Lecithin in Fett XV mit der Verkalkung zu vermuthen war, wurde die Kalksubstanz gleichfalls in die Untersuchung hineingezogen. Es möge gestattet sein, den Gang dieser speciellen Untersuchung in Kürze zu skizziren.

Die verkalkten Partien wurden möglichst sorgfältig von dem anhaftenden Gewebe getrennt und nach dem Trocknen im Vacuum zunächst mit Petroläther völlig entfettet. Alsdann wurde mit absolutem Alkohol extrahirt. Die alkoholischen Auszüge schieden beim Erkalten reichliche Mengen eines weissen Pulvers ab, das in viel heissem, absolutem Alkohol sich wieder langsam löste. Die nähere Untersuchung dieser Substanz ergab, dass sie aus den Calciumsalzen höherer Fettsäuren, also aus Kalkseifen, bestand.

In dem mit absolutem Alkohol erschöpften Rückstand konnte Calciumcarbonat sowie Calciumphosphat nachgewiesen werden; Magnesium war nur in geringen Spuren vorhanden, Oxalsäure feblte ganz. Die Bestimmung des Calciumcarbonats und -phosphats wurde derart durchgeführt, dass ein aliquoter Theil der mit Petroläther und absolutem Alkohol vorbehandelten Substanz mit verdünnter Schwefelsäure erwärmt und die entweichende Kohlensäure im Kaliapparat mit Lauge aufgenommen wurde. Ein anderer Theil des Objectes wurde mit verdünnter Salpetersäure erschöpft, das saure 
Filtrat mit Alkali übersättigt, eingedampft und der Rückstand eingeschmolzen. In dieser Oxydationsschmelze wurde der Gehalt an Phosphorsäure nach der Molybdänmethode bestimmt und auf tertiäres Calciumphosphat berechnet.

Nach dem Ergebniss dieser Bestimmungen bestand die Verkalkungsmasse aus:

$$
\begin{aligned}
& 29,50 \% \text { Kalkseife, } \\
& 28,61 \% \text { Calciumcarbonat, } \\
& 41,89 \% \text { tert. Calciumphosphat. }
\end{aligned}
$$

In der zur Verfügung stehenden Litteratur konnten keine Angaben darüber gefunden werden, dass die Betheiligung von Kalkseifen bei der Bildung von Verkalkungen oder von Kalkconcrementen schon beobachtet worden ist. Es soll hier noch bemerkt werden, dass an der Bildung dieser Kalkseifen alle 3 Fettsäuren des Lipomfettes, also Oelsäure, Palmitin- und Stearinsäure, betheiligt waren.

Die aus dem überaus hohen Lecithingehalt des Fettes XV gefolgerte Anwesenheit von Phosphorsäure in der Verkalkungsmasse ist also durch diesen Analysenbefund bestätigt worden.

Die Vertheilung der Phosphorsäure in dem in Frage stehenden Lipom ist nach dem bisher Mitgetheilten folgende: Die centralen Partien des Lipoms sind durch einen Kalkmantel umgrenzt, welcher ungefähr zur Hälfte aus Calciumphosphat und zu ungefähr je einem Viertel aus Calciumcarbonat und Kalkseifen bestand. Das in dieser centralen Gewebspartie vorhandene Fett Nr. XV enthält 7,21\% Lecithin, während das Fett des übrigen, weitaus grössten Theiles des Lipoms, Fett Nr. XIV, einen Lecithingehalt von nur $0,0284 \%$ aufweist.

Es ist nun gewiss beachtenswerth, dass trotz des ausserordentlich gesteigerten Phosphorumsatzes innerhalb dieses Lipoms der Lecithingehalt des Fettes XIV des Lipoms noch weit hinter dem Lecithingehalt der normalen Unterhautfette zurückbleibt. Diese Thatsache, in Verbindung mit dem ebenso niedrigen Lecithingehalt des Lipomfettes XII, könnte doch wohl in dem Sinne gedeutet werden, dass in den vorgeschrittenen Stadien der Lipome der Lecithingehalt des Fettes eine beträchtliche Erniedrigung erfahren hat. 


\section{Zusammenstellung.}

Von den Ergebnissen der vorstehenden Untersuchungen mögen folgende Punkte nochmals in kurzer Fassung hervorgehoben werden:

1. Das Fett des erwachsenen Menschen besteht im Wesentlichen aus den einfachen Glyceriden der Oelsäure, Palmitinsäure und Stearinsäure. Ausser geringen Spuren von niedrigen Fettsäuren konnten keine andern Säuren nachgewiesen werden.

2. Die chemische Zusammensetzung des Fettes ist sehr weitgehenden individuellen Schwankungen unterworfen.

3. In den ersten Lebensmonaten des Kindes zeigt das Fett desselben gegenüber dem Fett des Erwachsenen sehr charakteristische Unterschiede in dem viel höheren Gehalt an niedrigen Fettsäuren und dem geringeren Gehalt an Oelsäure.

4. Ein Einfluss des Ernährungszustandes des Individuums auf die chemische Zusammensetzung des Fettes konnte nicht beobachtet werden.

5. Das Fett der Lipome unterscheidet sich im Allgemeinen nicht wesentlich von dem Fett aus dem normalen Unterhautzellgewebe. Es darf aber als wahrscheinlich hingestellt werden, dass der Lecithingehalt des Fettes in sehr stark entwickelten Lipomen beträchtlich herabgesetzt wird.

6. Das Fett kann durch pathologische Processe ausserordentlich weitgehende Veränderungen erfahren.

7. Es konnte die Betheiligung von Kalkseifen bei dem Verkalkungsprocess beobachtet werden. 